\title{
NUMERICAL ANALYSIS AND EVALUATION OF EFFECTIVE SLAB WIDTH OF COMPOSITE CONTINUOUS BEAMS WITH SEMI-RIGID JOINT
}

\author{
Abdesselam Bahaz ${ }^{1, *}$, Salah Amara ${ }^{1}$, Jean-Pierre Jaspart ${ }^{2}$ and Jean-François Demonceau ${ }^{2}$ \\ ${ }^{1}$ Structures Rehabilitation and Materials Laboratory (SREML), Amar Telidji University of Laghouat, Algeria \\ ${ }^{2}$ Urban and Environmental Engineering (UEE) Department, University of Liege, Belgium \\ * (Corresponding author: E-mail: a.bahaz@lagh-univ.dz)
}

\section{A B S T RA C T}

The characterization of the structural behavior of composite beams is directly affected by the determination of the effective slab width. Various codes propose their own definitions of the effective width based on the beam span and the slab width parameters. However, the evaluation of the effective width may be influenced by other parameters. The aim of this work is to determine the most important factors affecting effective width for continuous composite beams with semi-rigid joints using numerical simulations. A three-dimensional finite element model of a composite continuous beam using explicitsolver available in ABAQUS is developed. The proposed model is validated through comparisons to available experimenta results. A modified model is proposed based on the so-validated model to study the influence of the composite beam-column joint stiffness on the effective width. Then, both numerical models are used to perform an extensive parametric study to investigate the influence of various parameters on the estimation of the effective slab width. The influence of slab width, the shear connection degree, and composite joint stiffness are particularly analyzed to find out the most important parameters influencing the effective width so that simplified equations for the calculation of the effective slab width are proposed.

\section{A R T I C L E H I S T O R Y}

$\begin{array}{ll}\text { Received: } & \text { 13 March } 2021 \\ \text { Revised: } & 21 \text { May } 2021 \\ \text { Accepted: } & 24 \text { May 2021 }\end{array}$

\section{K E Y W O R D S}

\section{Composite beams}

Effective width;

Numerical analysis;

Semi-rigid joints;

Shear-lag

\section{Introduction}

Composite steel-concrete continuous beams have been widely used in bridges and high-rise buildings in recent years because they consist of taking advantage of both materials. The effective slab width affects the determination of the section properties of composite beams, which is assumed in their calculation. The concept of effective slab width allows accounting for the shearlag phenomenon developing in the concrete slab, which occurs due to shear deformation in the slab plan when the longitudinal strain of a slab portion away from the steel beam is smaller than that in the portion close to the steel beam [1]. Many design codes [2-4] specify their effective widths for composite beams by considering the beam's span as the most important parameter influencing the effective width. However, they ignore the effect of the degree of shear connections and the initial stiffness of the beam-to-column composite joints on the effective slab width. Amadio et al. [5] conducted numerical analyses on the cantilever and simply supported composite beams to study the influence of shear connections deformability and loading level on the evaluation of effective widths. They presented a simple modification of the Eurocode [2] formula to estimate the effective width of composite beams subjected to hogging bending moments [6]. Salama et al. found that the beam span and the slab width significantly affect the effective width. Two formulas were proposed to calculate the effective width at the serviceability and ultimate states for simply supported composite beams [7]. Yuan et al. [1] proposed a simplified design formula for computing the effective width of the cantilever and simply supported beams based on two theoretical models. A parametric study was carried out to study the effect of concrete slab thickness, beam span, and slab width on evaluating the effective width. Lasheen et al. found that the slenderness ratio of the steel beam and the width-to-span ratio affect the effective width and loading level [8]. Two equations were provided to calculate the effective width at service and ultimate load states for simply supported composite beams. Al-Sherrawi et al. [9] performed a three-dimensional linearly elastic finite element analysis to study the effect of the interaction degree on the concrete slab's stress distribution in a composite continuous beam under concentrated loads.

Most of the existing studies [1,5-16] concerning the definition of the effective width are based on cantilever or simply supported beams. However, continuous beams or semi-continuous beams (i.e., beams with semirigid joints at their extremities) are regularly met in buildings; in these beams, regions subjected to sagging and hogging bending are identified. Thus, composite joint stiffness and reinforcement ratio in the hogging bending region should be taken into account to evaluate the effective slab width. This paper investi-

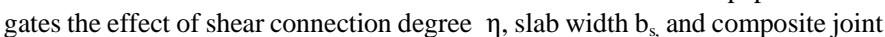
stiffness $S_{j, i n i}$ on the effective slab width of composite continuous and semi-continuous beams. In the next section, the definition of the effective width will be briefly reminded. Then, in Section 3, the numerical modeling assumptions will be presented, and the validation of the numerical model through comparisons with experimental results will be demonstrated in Section 4. In Section 5, a parametric study is conducted with the so-validated numerical model. Finally, the obtained results are discussed in Section 6, and conclusions are drawn in Section 7.

\section{Effective width definition}

Due to the shear-lag effect, longitudinal stress along the transverse direction of the concrete slab has a non-uniform distribution. The effective width $b_{e}$ is defined as the equivalent slab width having a constant stress distribution across it and sustaining stress equal to the maximum stress applied to the slab considering the actual stress distribution, so the Bernoulli assumption applies. Accordingly, the magnitude of the constant stress in the effective width is taken as equal to the peak longitudinal stress in the slab at the slab-beam junction, as shown in Fig. 1. As a result, the mathematical definition of effective width is:

$b_{e}=\frac{\int_{0}^{b_{s}} \sigma_{x} d z}{\left(\sigma_{x}\right)_{\max }}$

where:

$b_{e}$ is the effective width;

$b$ is the concrete slab width;

$\sigma_{x}$ represents the normal stress in the slab at the top surface in the longitudinal direction.

$\left(\sigma_{x}\right)_{\max }$ represents the maximum normal stress for $0 \leq z \leq b_{s}$.

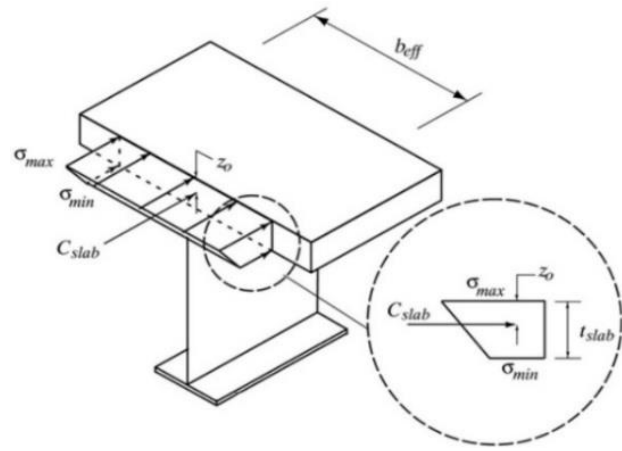

Fig. 1 Effective slab width definition for a hogging moment section [10] 
In the presented study, the effective widths have been predicted using $\quad \mathrm{Eq}$ (1) and solving the integral. These calculations were carried out using MATLAB® [17] and an approximate method based on the trapezoidal rule.

\section{Finite element modeling assumptions}

The objective is to simulate the behavior of continuous and semi-continuous composite beams using the ABAQUS software [18]. Due to symmetry in geometry, loading, and boundary conditions, just one-quarter of the investigated beams are modeled, as shown in Fig. 2 and Fig. 3. A linear reduced integration quadrilateral shell element (S4R) is used to model the concrete slab and the steel beam. This element allows us to obtain a good prediction of the steel beam behavior and, in particular, of local buckling effects [19] and have a computationally efficient model involving a limited number of degrees of freedom. Steel reinforcing bars are modeled as smeared layers with constant thickness in the shell element. The load-slip behavior of shear studs is simulated using a nonlinear connector element "Cartesian + Align," which connects a beam flange node with a slab node at the steel-to-concrete interface where the shear connectors are located, as shown in Fig. 3. In the direction perpendicular to the beam axes, a rigid connection is assumed (the uplift is neglected), while the slip-load behavior in the direction parallel to the beam axis is derived from the nonlinear elastic law proposed by Aribert [20], as follows:

$$
Q=Q_{\max }\left(1-e^{-0.7 \gamma}\right)^{0.56}
$$

where:

$\gamma$ and $Q$ are the relative slip between the slab and the steel beam and the shear force, respectively (see Fig. 4). The maximum shear studs' resistance $Q_{\max }$ is calculated according to Eurocode 4 [2].

\subsection{Material models}

By specifying the nominal stress-strain relationship, which is calculated using Yun et al. [21] proposed bilinear plus nonlinear hardening material model, material nonlinearity is included in the finite element model. The obtained true stress and strain relationships are tabulated in ABAQUS [18]. A concrete damaged plasticity (CDP) method is selected to define the plastic behavior of the concrete; hence an elastic-plastic behavior including strain-softening can be defined. The CDP model proposed by Carreira et al. [22] is adopted for this study. The normalized uniaxial stress-strain relationship for concrete under compression and tension is illustrated in Fig. 5.

\subsection{Contact and constraint conditions}

A general contact procedure is selected with a HARD contact property specified in the normal direction to define the interaction at the interface between the steel beam and the concrete slab. The PENALTY approach with a friction coefficient of 0.1 is used for the tangential response, which was referenced from the study of Al-Jabri et al. [23]. A sensitivity analysis was done by Dai et al. [24] revealed that using a wide range of friction coefficient values had no impact on the simulation results. A rigid body constraint is used to link the loading surface's nodes to the point where a controlled displacement is applied.

\subsection{Solution scheme}

Because of the numerical instabilities in the nonlinear analysis during concrete cracking, convergence is always complicated to achieve when using the general static procedure. For this reason, RIKS method is often used to avoid such convergence issues. However, this procedure is not relevant when material damage is included. An alternative consists of using the EXPLICIT procedure to prevent such problems and speed up convergence; this is the selected solution in this study. A quasi-static analysis should be established within the explicit solver to prevent the dynamic effect during the EXPLICIT analysis. This analysis necessitates the application of a smooth loading, which means that the acceleration must only change by a small amount from one increment to the next to apply the load smoothly. If the acceleration is smooth, the velocity and displacement changes would be smooth as well. A reasonable loading rate of 1 $\mathrm{mm} / \mathrm{min}$ was selected after checking different loading rates on the model, while the initial stable time increment is $10^{-6} \mathrm{~s}$.
Table 1

Geometrical and mechanical characteristics of the investigated specimens (based on test results) [25]

\begin{tabular}{|c|c|c|c|}
\hline Property & $\begin{array}{l}\text { Yield } \\
\text { strength } \\
\left(\mathrm{N} / \mathrm{mm}^{2}\right)\end{array}$ & $\begin{array}{l}\text { Ultimate } \\
\text { strength } \\
\left(\mathrm{N} / \mathrm{mm}^{2}\right)\end{array}$ & Other properties \\
\hline Beam web & 362 & 451 & \\
\hline Bottom beam flange & 285 & 380 & Steel grade S235 \\
\hline Top beam flange & 281 & 385 & \\
\hline Reinforcement & 500 & I & $\begin{array}{l}14 \text { bars at hogging zone with } 2 \mathrm{~m} \\
\text { in length and } 6 \mathrm{~mm} \text { in diameter. }\end{array}$ \\
\hline Shear connectors & 37.9 & I & $\begin{array}{l}h_{s c}=50 \mathrm{~mm} \text { and } \mathrm{D}=12.7 \mathrm{~mm} \text {; } \\
14 \text { studs with } 200 \mathrm{~mm} \text { of spacing } \\
\text { in two rows at the sagging zone } \\
\text { and } 26 \text { studs with } 100 \mathrm{~mm} \text { of } \\
\text { spacing in two rows at the } \\
\text { hogging zone. } \\
\mathrm{E}=27800 \mathrm{MPa}\end{array}$ \\
\hline
\end{tabular}

Table 2

Comparison between ultimate loads for FEM and Experiments

\begin{tabular}{|c|c|c|c|c|c|c|}
\hline \multirow{2}{*}{$\begin{array}{l}\text { Specimen } \\
\text { ID [25] }\end{array}$} & \multicolumn{2}{|c|}{$\begin{array}{l}\text { Failure load } \\
\underline{Q}_{u}(k N) \\
\end{array}$} & \multirow[t]{2}{*}{$\mathrm{EXP} / \mathrm{FE}$} & \multicolumn{2}{|c|}{$\begin{array}{l}\text { Mid-span defl. } \\
\text { at } Q=80 \mathrm{kN}\end{array}$} & \multirow[t]{2}{*}{ EXP/FE } \\
\hline & FE & EXP & & FE & EXP & \\
\hline P03 & 190 & 176 & 0.93 & 1.74 & 1.31 & 0.75 \\
\hline P04 & 211 & 179 & 0.85 & 1.73 & 1.35 & 0.78 \\
\hline P05 & 179 & 189 & 1.06 & 1.73 & 1.25 & 0.72 \\
\hline P06 & 204 & 232 & 1.14 & 1.73 & 1.43 & 0.83 \\
\hline P07 & 177 & 175 & 0.99 & 1.73 & 1.44 & 0.83 \\
\hline P08 & 189 & 210 & 1.11 & 1.73 & 1.48 & 0.86 \\
\hline P09 & 190 & 187 & 0.98 & 1.73 & 1.36 & 0.79 \\
\hline \multirow[t]{2}{*}{ P10 } & 211 & 231 & 1.09 & 1.73 & 1.25 & 0.72 \\
\hline & & $\mathrm{AV}$ & 1.02 & & $\mathrm{AV}$ & 0.78 \\
\hline
\end{tabular}

\section{Validation of the finite element model}

The proposed FE model's validity is examined by comparing the soobtained numerical results with those determined experimentally by Janss et al. [25]. In this test campaign, ten continuous composite beams were tested under a static control load to study the effect of reinforcement ratio at the internal support section and the effect of concrete strength on the structural behavior. Beams P01 and P02 were tested without reinforcing bars; thus, they are excluded from this study. The details of the investigated beams are shown in Fig. 2 and Table 1. The numerical and experimental results are compared in terms of loading capacity and maximum mid-span deflection.

Table 2 lists the ultimate loads, the mid-span deflections for a specifically applied load $(Q=80 \mathrm{kN})$, and the ratios between experimental tests and numerical results. Comparing the load versus deflection curves as reported in Fig. 6 demonstrates that finite element results are highly correlated with experimental results. To ensure the accuracy of the Explicit solution, the kinetic energy (KE) should be less than $10 \%$ of the internal energy (IE) [18], which is the case here. Thus, the explicit solution can be considered as quasi-static by reducing the dynamic effect even at failure load, as shown in Fig. 7. Finally, the FE model developed herein is capable of accurately predicting the behavior of continuous composite beams. In particular, as reflected in Table 2, the accuracy of the $\mathrm{FE}$ analysis in predicting the ultimate load ranges from $-15 \%$ to $15 \%$, which is assumed to be reasonable.

\section{Parametric study}

In order to evaluate the effect of the various parameters (i.e., concrete slab width, shear connection degree, and composite joint stiffness) on the effective width, a parametric study is performed as described hereafter. The geometric and material properties of the P03 specimen [25] were adopted as a reference from which the different investigated parameters are varied. A slab width of $b_{s}$ $=2 \mathrm{~m}$ is adopted to study the effect of the shear connection degree and the composite 


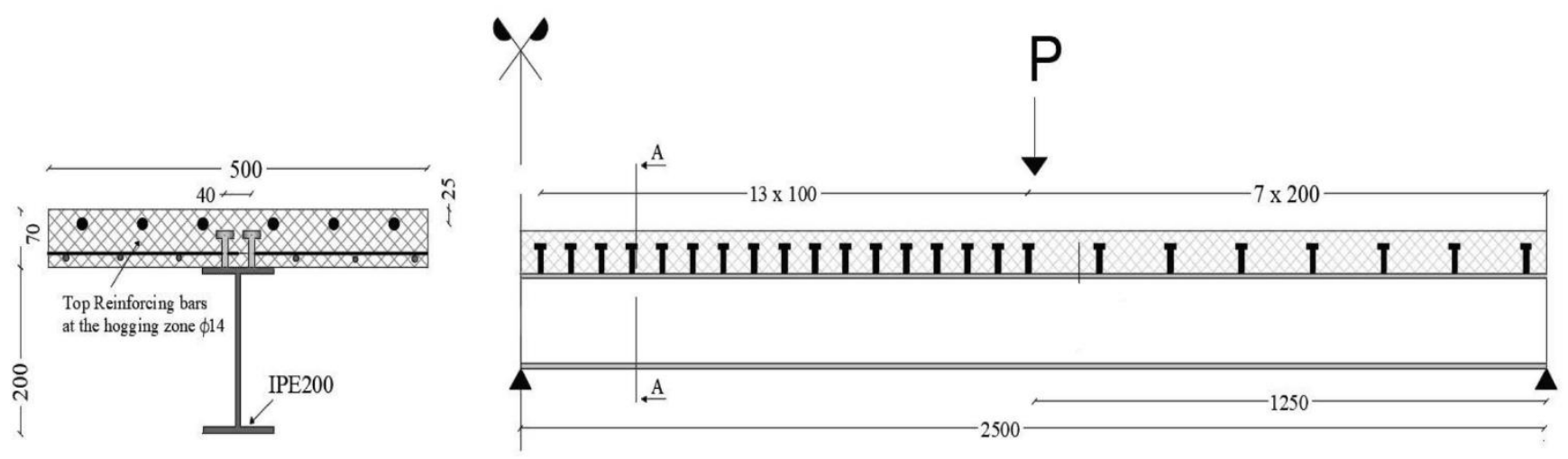

A-A cross section

Fig. 2 Geometry of the investigated beam specimen (dimensions in $\mathrm{mm}$ )

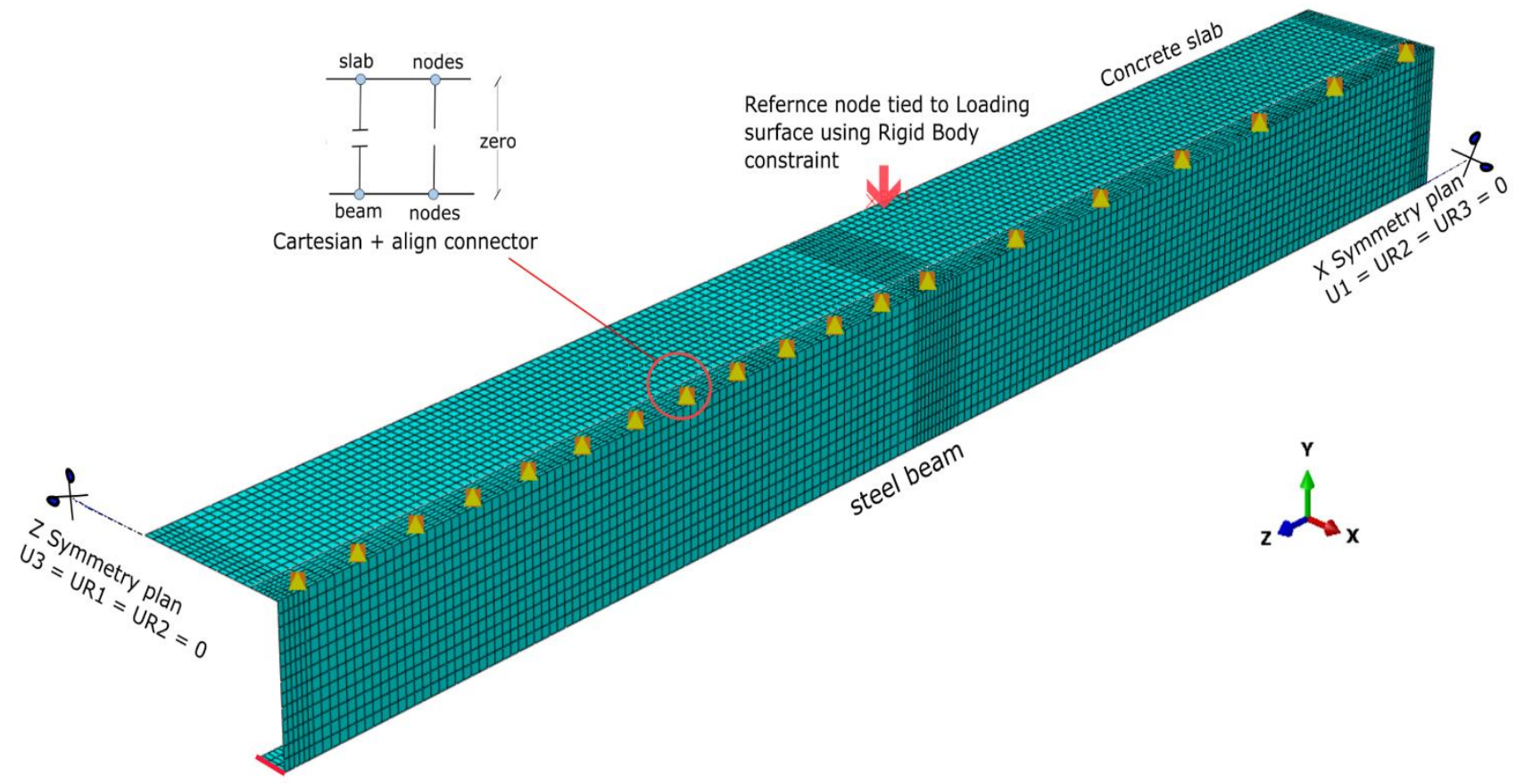

Internal support

$\mathrm{U} 1=\mathrm{U} 2=\mathrm{U} 3=0$

Fig. 3 Finite element mesh and boundary conditions of one-quarter of the composite continuous beam

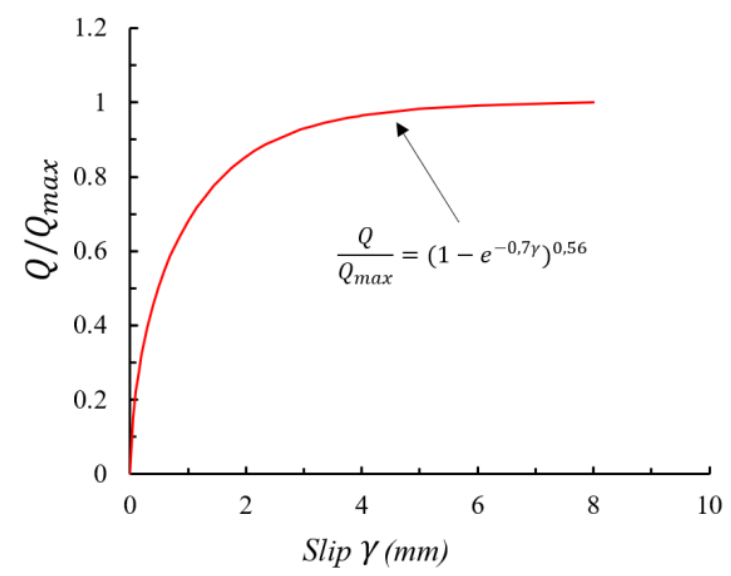

Fig. 4 Nonlinear constitutive law used in the finite element model 


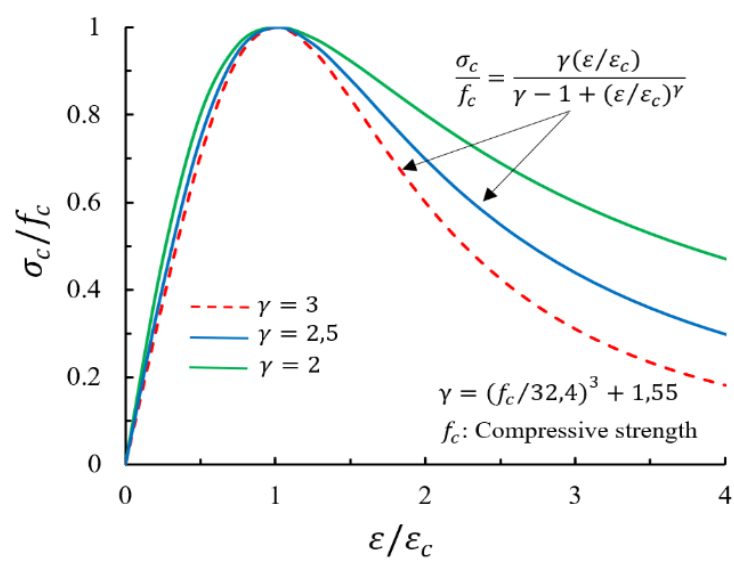

(a) Compression

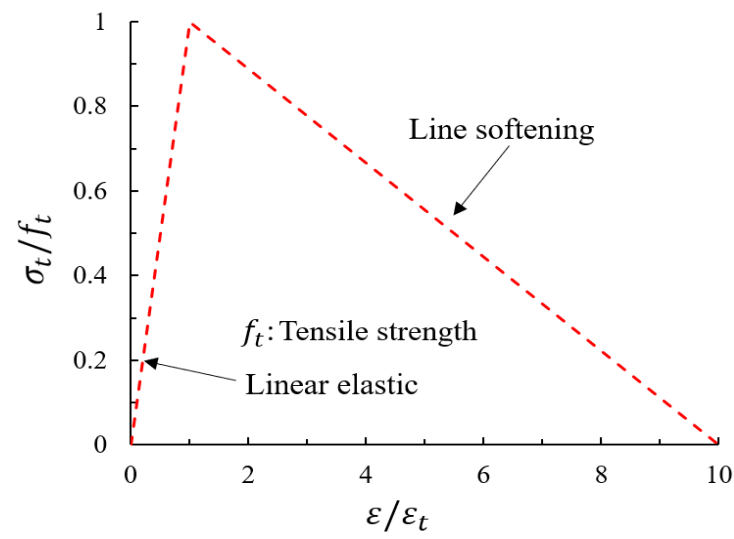

(b) Tension

Fig. 5 Stress-strain relationship of the concrete (Carreira et al. [21])

joint stiffness so that the effective width will be evaluated easily along the beam span. As mentioned previously, the investigated parameters are:

- The effect of the shear connection degree $\eta$ (see Section 5.1)

- The effect of the concrete slab width $b_{\mathrm{s}}$ (see Section 5.2) and;

- $\quad$ The effect of the initial stiffness $S_{j \text {, ini }}$ of a composite joint located at the level of the internal support (see Section 5.3);

The critical sections of the investigated beam are located at the level of the internal support (hogging bending zone) and the loading points (sagging bending zone). Consequently, the effective widths are evaluated for those critical sections for two loading levels: at $Q=Q_{e}$, i.e., when the structural behavior of the composite beam is still in the elastic domain, and at ultimate load $Q_{u}$.

\subsection{Effect of shear connection degree}

Shear connectors are modeled as explained in Section 3. A full shear connection degree $(\eta=1)$ is adopted in the hogging bending region respecting the recommendation of Eurocode 4 [2], while four shear connection degrees are investigated, as shown in Table 3, for the sagging moment region. Fig. 8 and Fig. 9 highlight the influence of the shear connection degree on the effective width at internal support and mid-span sections. It is demonstrated that the shear connection degree has a limited and negligible influence on the effective width for the investigated composite continuous beams; this confirms the results obtained by Chen et al. [26].

\subsection{Effect of slab width}

Five beams with different slab widths ranging from $0.5 \mathrm{~m}$ to $2.5 \mathrm{~m}$ were simulated, keeping the same reinforcement ratio $(\mu=2.6 \%)$ and rebar crosssection $(\phi=14 \mathrm{~mm})$ as in the tested specimens [24]. Since the shear connection degree does not influence the effective width as demonstrated previously. The node-to-surface tie constraint option available in ABAQUS [18] is used to achieve a full connection degree between the concrete slab and the steel beam.

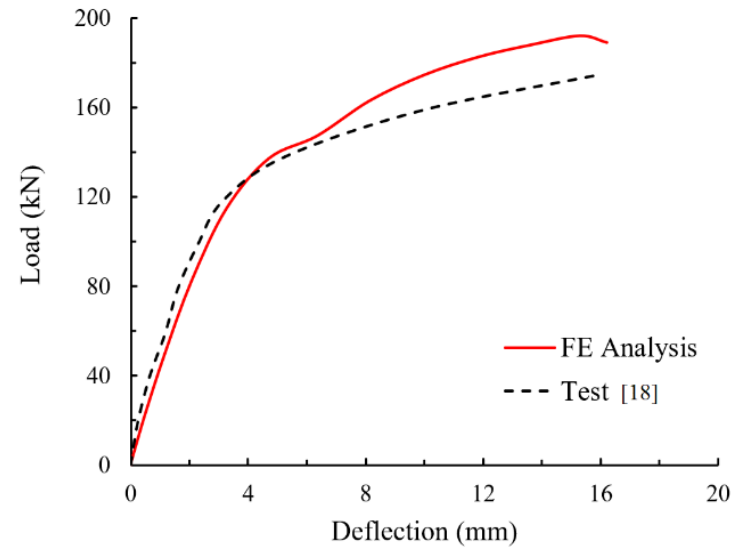

Fig. 6 Comparison between the predicted and measured Mid-span deflection

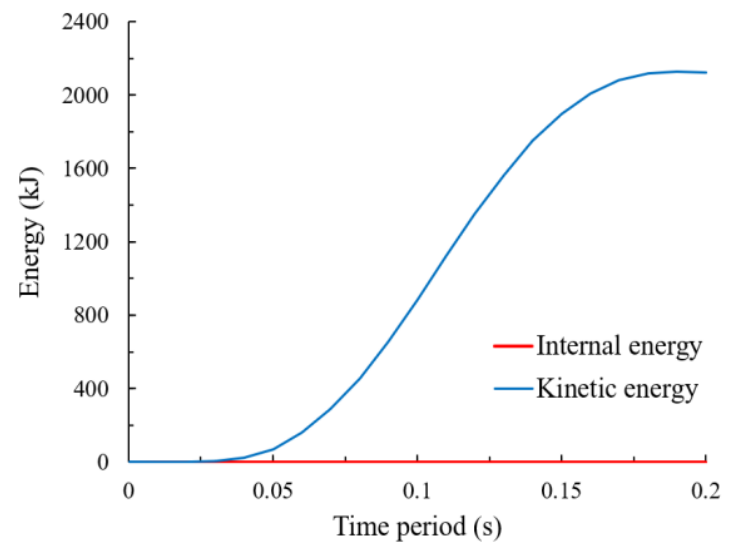

Fig. 7 Comparison between the predicted kinetic and internal energy

Table 3

Details of beams for the shear connections parametric study

\begin{tabular}{lll}
\hline \multirow{2}{*}{ Degree of shear connections $\eta$} & \multicolumn{2}{c}{ Number of shear connectors } \\
\cline { 2 - 3 } & Hogging zone & Sagging zone \\
\hline 1 & 30 & 20 \\
0.76 & 26 & 14 \\
0.60 & 20 & 10 \\
0.44 & 16 & 6 \\
\hline
\end{tabular}

Therefore, reduced FE model size and convergence time are ensured. Fig. 10 and Fig. 11 compare the predicted effective width and the effective width proposed by the code [2] at midspan and internal support under both loading levels $Q_{e}$ and $Q_{u}$. It is clear from Fig. 10 that the code overestimates the effective width at mid-span for the smallest slab width $(b / L \leq 0.3)$, while it is underestimated for the higher $b_{s} / L$ ratios. From Fig. 11, it can be seen that the effective width proposed by the code [2] is consistently underestimated at the internal support compared to the ones proposed by the code [2] and Amadio et al. [5]. Fig. 12 shows a comparison between the predicted effective width and the effective width proposed by some previous researchers and codes in the elastic domain at the midspan section. The computed effective width for the investigated composite continuous beams is smaller than those proposed by Salama et al. [7] and Yuang et al. [1]. In contrast, the predicted effective width at internal support becomes more prominent than the one proposed by Amadio et al. [5] when $b / L \geq 0.4$, as shown in Fig. 11.

\subsection{Effect of shear connection degree}

In order to simulate the presence of a semi-rigid composite joint at the level of the internal support, the beams pan of the previous FE model was reduced by $76 \mathrm{~mm}$ at the internal support to place a rectangular bar at the level of the bottom flange, as illustrated in Fig. 13. It is possible to simulate the presence of a joint with different stiffness levels by playing on the mechanical properties of this bar. 


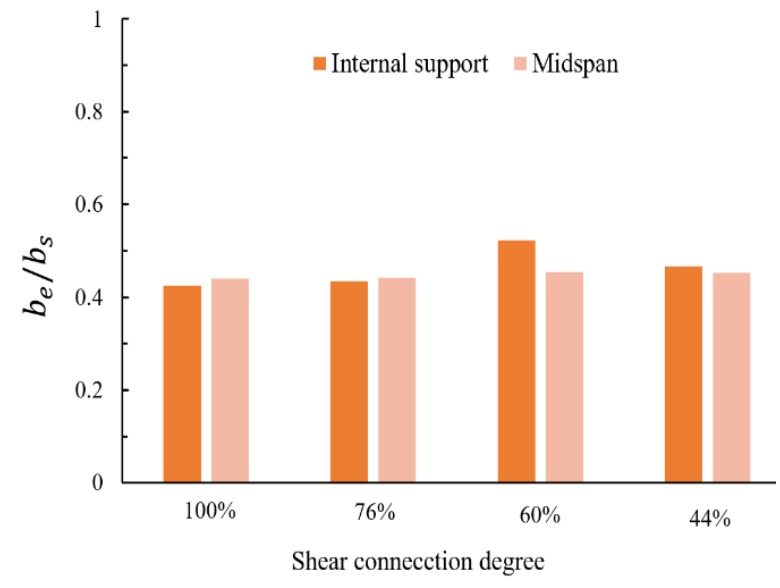

Fig. 8 Effect of the shear connection degree on the effective width at elastic loading level $\mathrm{Q}_{\mathrm{e}}$

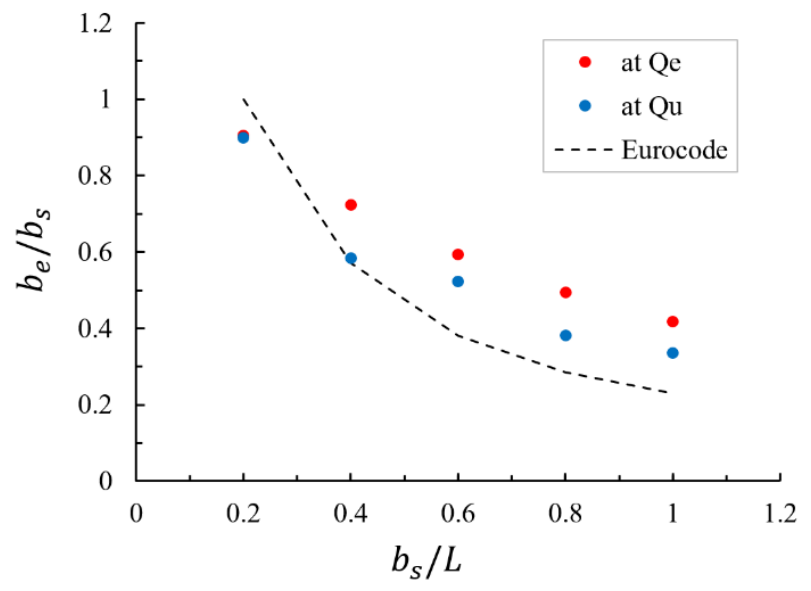

Fig. 10 Comparison between the predicted $b_{e}$ and $b_{e}$ proposed by the code [2] at mid-span section

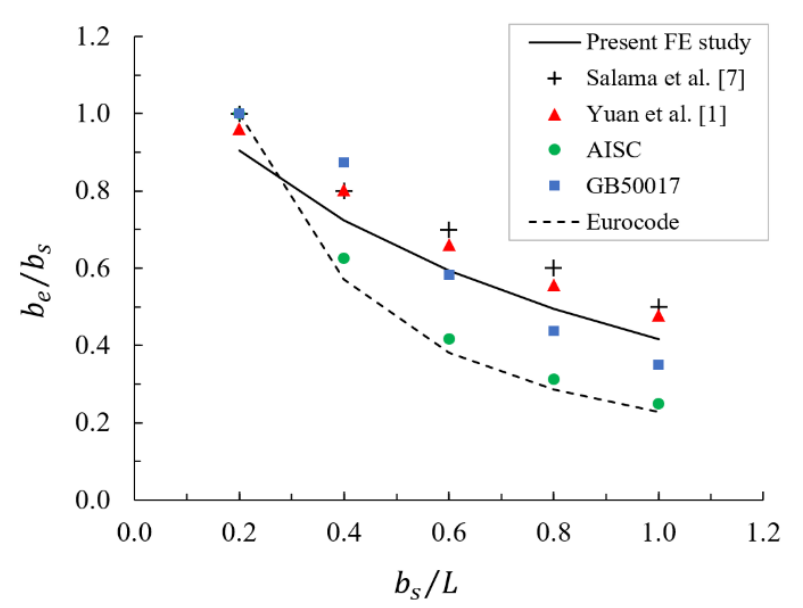

Fig. 12 Comparison between the predicted $b_{e}$ and $b_{e}$ calculated using previously proposed formulas at mid-span section

The rectangular bar is assumed to have a perfectly elastic behavior to avoid any failure at its level. In addition, a hole of $76 \times 80 \mathrm{~mm}$ is created in the concrete slab to simulate the presence of a HEA 160 column passing through the slab. With such modeling, the slab is activated in tension, which means that, in practice, only the reinforcement is activated, while the rectangular bar activates in compression. The rectangular bar and the steel beam's bottom flange were merged to prevent any relative movement between the two surfaces (see Fig. 13). $2 \mathrm{~m}$ of width is selected for the concrete slab to perfectly capture the shear lag phenomena. The composite joint model was checked through comparison to the FE model of the continuous beam, assuming a high stiffness

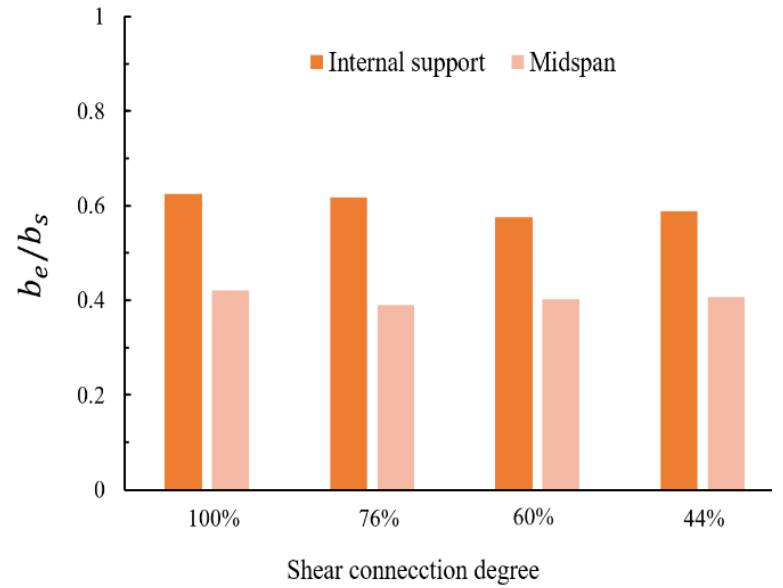

Fig. 9 Effect of the shear connection degree on the effective width at ultimate loading level $\mathrm{Q}_{\mathrm{u}}$

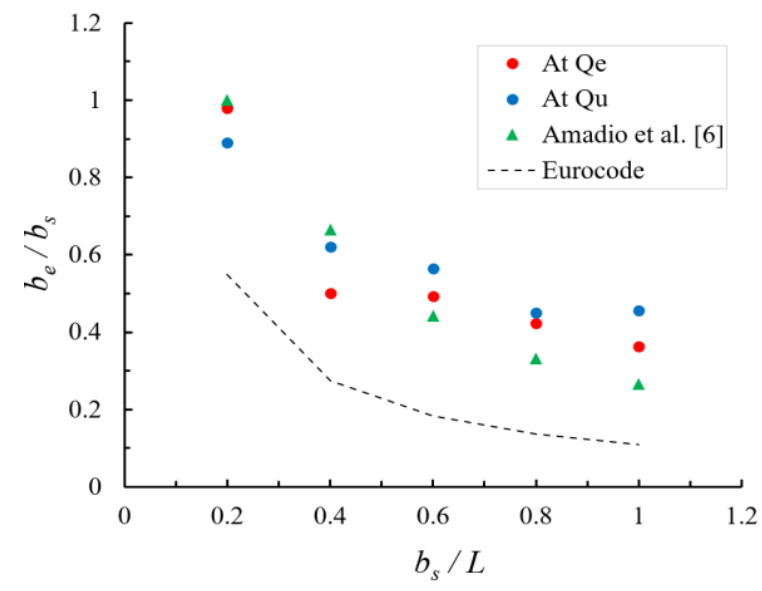

Fig. 11 Comparison between the predicted $b_{e}$ and $b_{e}$ proposed by the code [2] at the internal support section

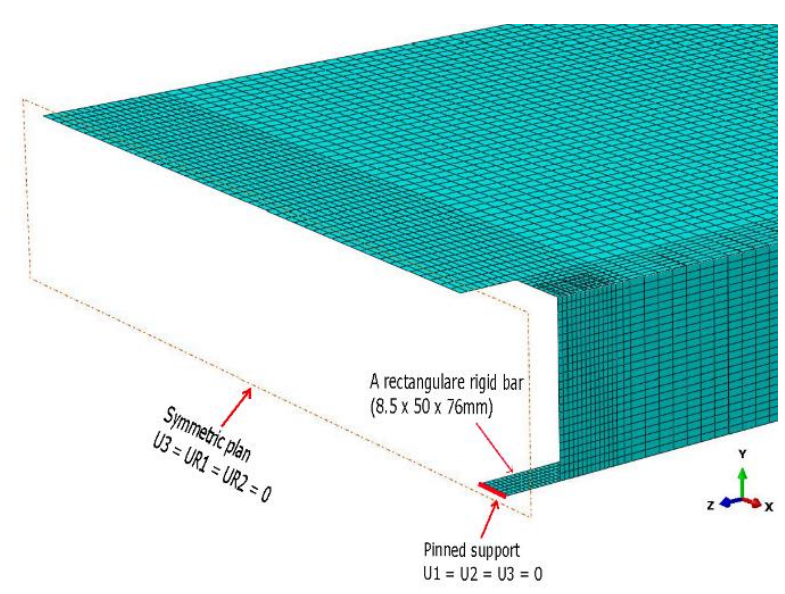

Fig. 13 Details and boundary conditions of the proposed composite joint model

for the rectangular bar, i.e., assuming a rigid joint at the level of the internal support. It can be observed from Fig. 15 that the composite joint model predicts almost the same mid-span deflection as the previously adopted FE model, which validates the proposed model. As previously mentioned, the bar stiffness EA/L is calibrated to simulate different composite joint initial stiffness $S_{j \text {, ini }}$. The bar's stiffness and the contribution of the reinforcement at the internal support must be considered for computing the composite joint's rotational stiffness. This joint stiffness is calculated according to EC3 [27] and EC4 [2], as follows:

a. Lever arm z between the reinforcement and the rectangular bar (see Fig. 14): 
$z=h_{a}-0.5 t_{f b}+h_{c}-a_{c s}$

$=200-0.5 \times 8.5+70-25=241 \mathrm{~mm}$

where:

$h_{a}$ is the nominal height of the steel beam;

$t_{f b}$ is the beam flange thickness;

$h_{c}$ is the concrete slab thickness;

$a_{s c}$ is the longitudinal reinforcement cover.

b. Stiffness coefficient to be considered for the rebar $k_{21}$ [2]:

$k_{21}=k_{\text {slip }} \times k_{s, r}$

where:

$k_{\text {slip }}$ is the reduction factor to account for possible shear connection slips;

$k_{s, r}$ is the stiffness coefficient for the reinforcement.

In our case, $k_{\text {slip }}=1$ because a full shear connection degree $(\eta=1)$ is adopted in the FE model, and $k_{s, r}$ is equal to:

$k_{s, r}=\frac{A_{s, r}}{h \frac{(1+\beta)}{2}+K_{\beta}}$

where:

$k_{\beta}=\beta\left(4.3 \beta^{2}-8.9 \beta+7.2\right)$

$A_{s, r}$ is the cross-sectional area of the longitudinal reinforcement in row $r$ within the effective slab width;

$h$ is the depth of the column's steel section;

$\beta$ is the transformation parameter.

In our case, we have a double-sided beam-to-column joint with equal beam moments on each side $\left(M_{b l, E d}=M_{b 2, E d}\right)$. Accordingly, $\beta \rightarrow \beta_{1}$ is equal to 0 according to Eurocode 3 [25].

Finally, the initial stiffness of the simulated joint can be estimated using the following formula:

$S_{j, \text { ini }}=\frac{E_{a} \times z^{2}}{\sum\left(\frac{1}{k_{i}}\right)}=\frac{210000 \times 241 ?}{\frac{1}{k_{21}}+\frac{1}{k_{b a r}}}$

where:

$k_{b a r}$ is the stiffness coefficient of the bar equal to $n A / L$ with $n=E_{b a r} / E_{a}$.

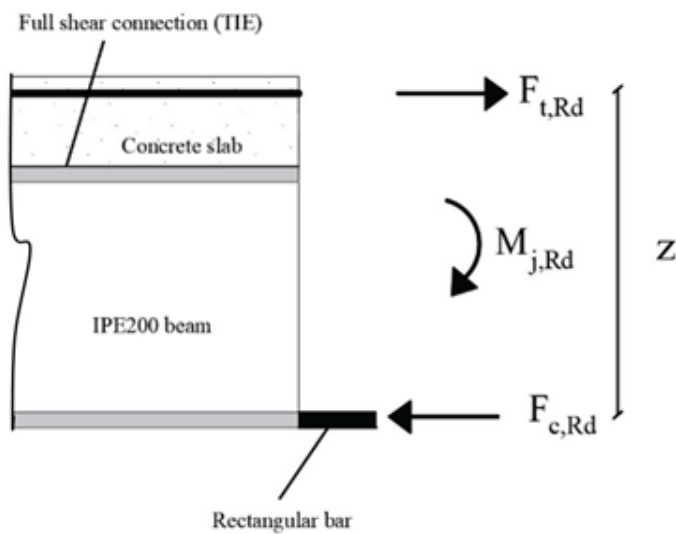

Fig. 14 Internal efforts distribution in the hogging bending moment for the proposed composite joint model

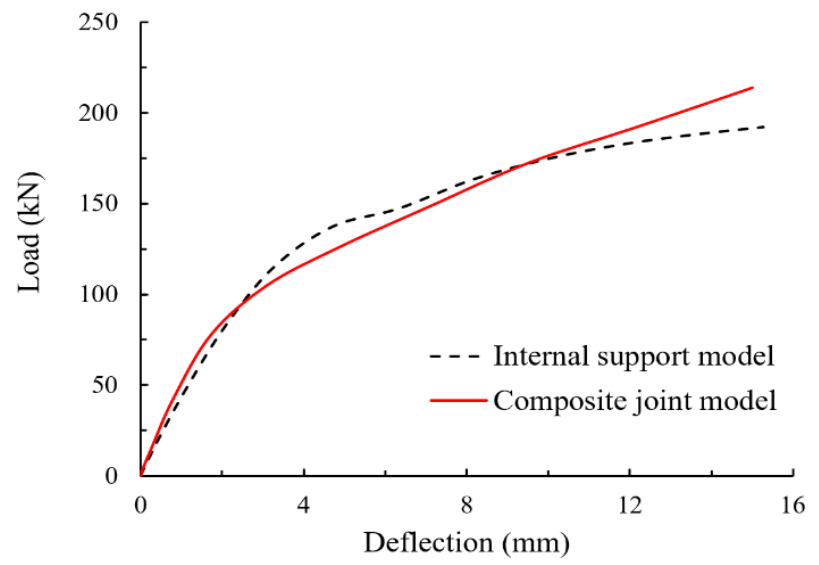

Fig. 15 Effect of the bar stiffness $S_{j, \text { bar }}$ on the mid-span deflections and ultimate loads

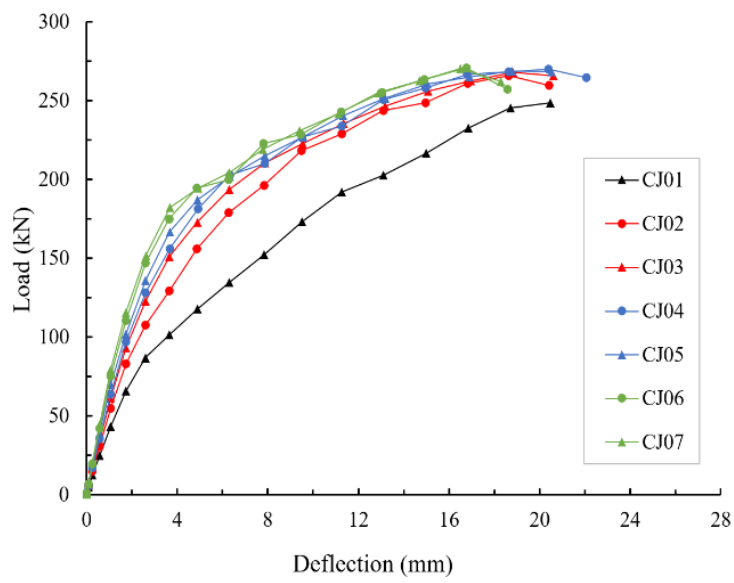

Fig. 16 Mid-span deflection for the proposed composite joint model and the one previously validated in Section 4

Table 4 summarises the considered initial stiffness for the composite joint $S_{j, \text { ini }}$ for the investigated beams. Fig. 16 shows the effect of the composite joint stiffness on ultimate load and maximum mid-span deflection. Globally, it can be seen that the beam stiffness decreases as the composite joint stiffness decreases, as expected, while the initial joint stiffness has almost no effect on the ultimate resistance of the composite beam for $S_{j, \text { ini }} \geq 65 \mathrm{MN} . \mathrm{m} / \mathrm{rad}$. The predicted deformations and Von Mises stresses distribution for beam CJ07 are presented in Fig. 17 and Fig. 18 as an example. It can be observed from Fig. 20 that at the ultimate loading state, the initial joint stiffness affects the effective width slightly at the joint level (hogging moment zone).

In contrast, in the elastic domain, the effective width increases significantly with the initial stiffness. However, its value decreases slightly with the increase of the initial stiffness shows at mid-span. The reason for such behavior is that the shear lag shrinks with the increase of the initial joint stiffness, and the effective width is becoming smaller, as shown in Fig. 20.

Table 4

Details of beams for the slab width parametric study

\begin{tabular}{|c|c|c|c|c|c|c|}
\hline \multirow[t]{2}{*}{ Beam ID } & \multirow{2}{*}{$\begin{array}{l}\text { Failure } \\
\text { load } Q_{u} \\
(\mathrm{kN})\end{array}$} & \multirow{2}{*}{$\begin{array}{l}\text { Maximum } \\
\text { deflection } \\
\delta_{\max }(\mathrm{mm})\end{array}$} & \multicolumn{2}{|c|}{$\begin{array}{l}b_{e} \text { at the joint } \\
\text { region }(\mathrm{mm})\end{array}$} & \multirow{2}{*}{$\begin{array}{l}E_{b a r} \\
(\mathrm{GPa})\end{array}$} & \multirow{2}{*}{$\begin{array}{l}S_{j, i n i} \\
(\mathrm{MN} \cdot \mathrm{m} / \mathrm{rad})\end{array}$} \\
\hline & & & at $Q_{e}$ & at $Q_{u}$ & & \\
\hline CJ01 & 248 & 20 & 350 & 579 & 210 & 41.60 \\
\hline CJ02 & 266 & 19 & 278 & 709 & 840 & 64.70 \\
\hline CJ03 & 268 & 19 & 393 & 732 & 1680 & 98.30 \\
\hline CJ04 & 268 & 20 & 451 & 706 & 2100 & 114.40 \\
\hline CJ05 & 270 & 19 & 558 & 690 & 4200 & 151.40 \\
\hline CJ06 & 270 & 17 & 627 & 720 & 8400 & 178.80 \\
\hline CJ07 & 270 & 16 & 647 & 711 & 21000 & 191.90 \\
\hline
\end{tabular}




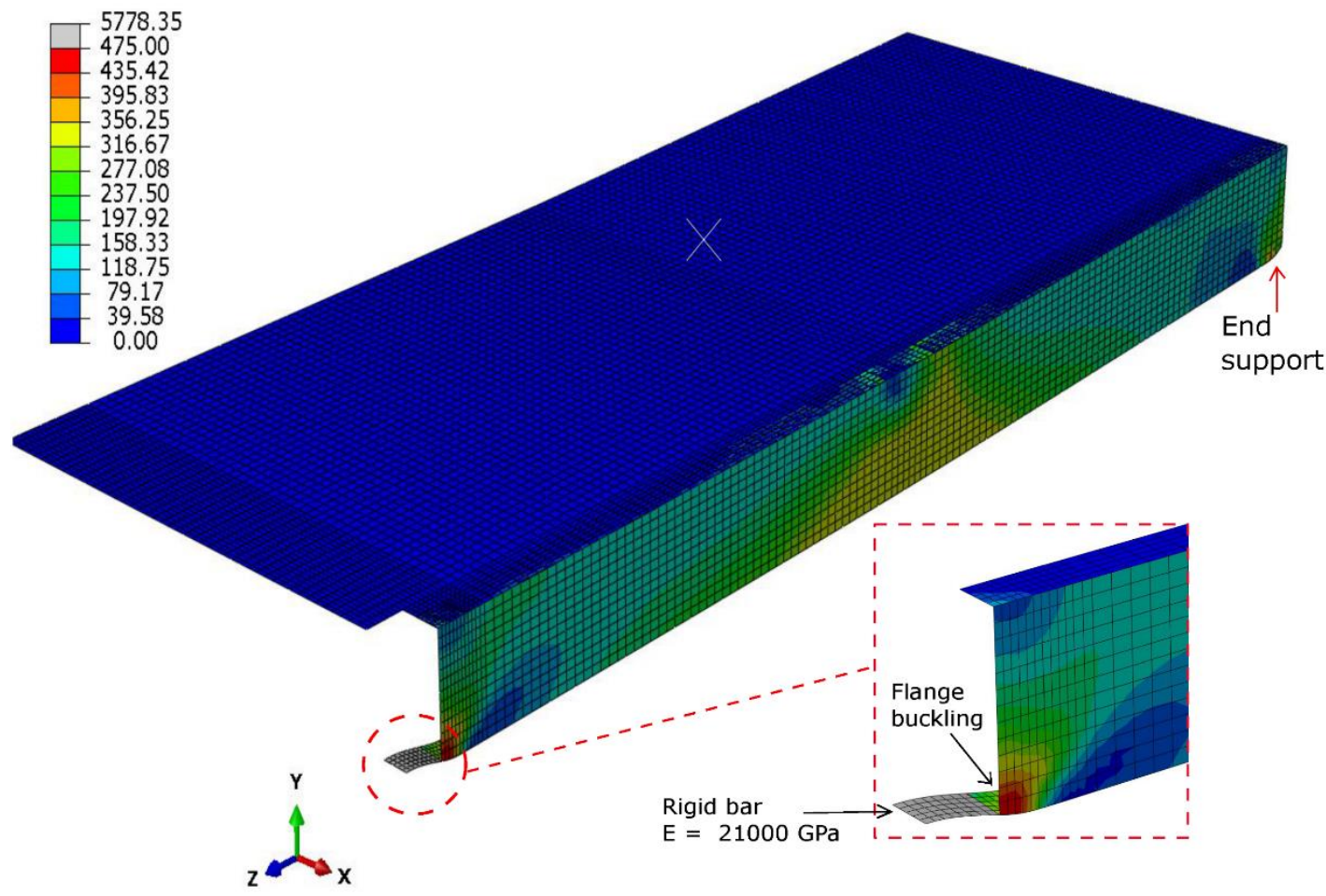

Fig. 17 Predicted stress distribution and deformation for CJ07 specimen at failure load

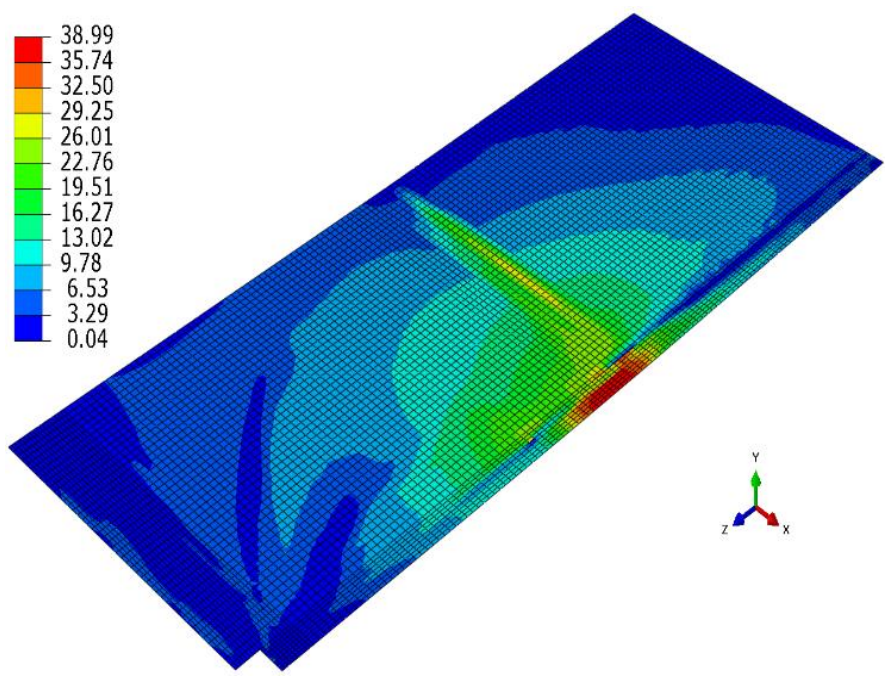

Fig. 18 Von Mises stress's distribution in the concrete slab for CJ07 specimen at failure load

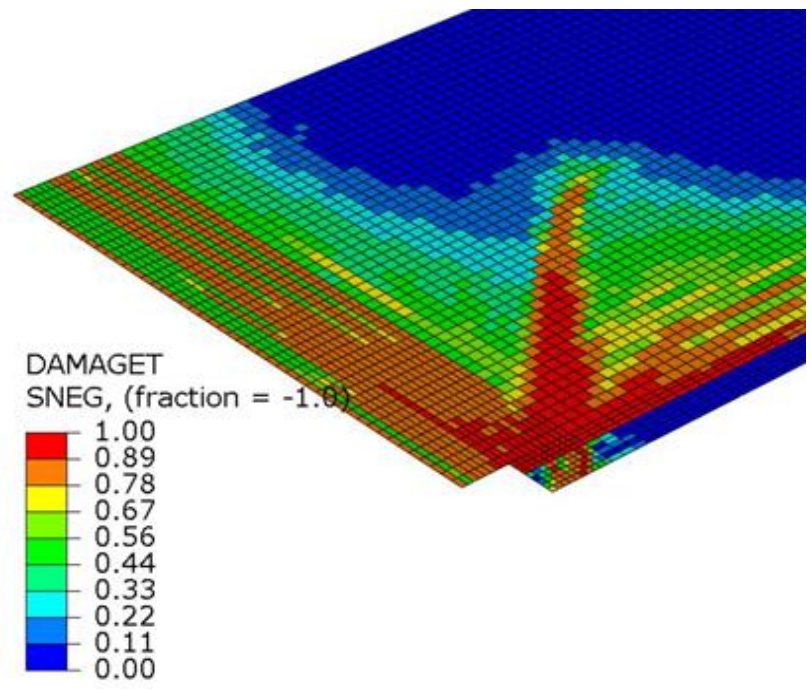

Fig. 19 Predicted concrete tension failure in the composite joint region for at ultimate load

\section{Discussion of the obtained results}

From the conducted parametric studies, it can be concluded that the main parameters affecting the effective slab width are $\mathrm{b}_{\mathrm{s}}$ (or, more precisely, the $b_{s} / L$ ratio) and $S_{j, \text { ini }}$. The effects of these two parameters on the effective width are discussed hereafter.

\subsection{Effect of slab width $b_{s}$}

In Fig. 12, the effective widths proposed by Eurocode [2], AISC [4], and GB50017 [3] for the midspan section are compared with the present FE results and the formulas proposed by Yuan et al. [1] and Salama et al. [7]. The effective width proposed by different codes is not in good agreement with the numerical results. Indeed, the value of $\mathrm{b}_{\mathrm{e}}$ is underestimated for $b_{s} / L \geq 0.4$ using the Eurocode and AISC codes. Using the GB50017 code, $b_{e}$ is slightly underestimated for $b_{s} / L \geq 0.6$, and below those ratios, $b_{\mathrm{e}}$ is overestimated However, the values of $b_{e}$ found using simplified formulas recommended by Yuan et al. [1] and Salama et al. [7] are overestimated compared to the present FE results. Moreover, the effective width formulas proposed by Amadio et al. [6] and in the Eurocode [2] for the internal support section give approximately the same values as the FE results for $b_{s} / L \geq 4$ (see Fig. 11). However, those values of $b_{e}$ are underestimated compared to FE results when the ratio $b_{\delta} / L$ is more significant than 0.6 at both loading levels $Q_{e}$ and $Q_{u}$. As shown in Fig. 19, significant cracks are developed in the hogging moment zone at the ultimate limit state for the smallest slab widths $b_{s} \leq 0.2 L$. Based on the obtained results from the parametric study and the regression method, the following simplified formulas has been calibrated to predict the effective width of the continuous composite beams in the elastic domain and at failure load, respectively:

\section{- At joint region:}

$b_{e} / b_{s}=-0.36 \times \ln \left(b_{s} / L\right)+0.32$

$b_{e} / b_{s}=-0.278 \times \ln \left(b_{s} / L\right)+0.42$

- At midspan:

$b_{e} / b_{s}=-0.303 \times \ln \left(b_{s} / L\right)+0.43$

$b_{e} / b_{s}=-0.347 \times \ln \left(b_{s} / L\right)+0.32$ 


\subsection{Effect of the joint initial stiffness $S_{j, \text { ini }}$}

From Fig. 21, it can be seen that the effective width increases significantly with the increase of the initial stiffness $S_{j, \text { ini }}$ at $Q \leq Q_{e}$ loading levels, while it increases slightly at the mid-span section (see Fig. 21). Therefore, its effect has to be taken into account at those levels. Accordingly, new simplified equations are developed to evaluate the effective width at mid-span and joint regions in the elastic domain and failure load. The coefficients of the following equations are determined based on a regression method:

- At joint region:

$b_{e} / b_{s}=0.0012 \times S_{j, \text { ini }}+0.23$

$b_{e} / b_{s}=0.0002 \times S_{j, \text { ini }}+0.64$

- At midspan:

$b_{e} / b_{s}=-0.0004 \times S_{j, i n i}+0.57$

$b_{e} / b_{s}=0.0004 \times S_{j, \text { ini }}+0.33$

where the unit of the initial stiffness $S_{j, \text { ini }}$ is $(\mathrm{MN} \cdot \mathrm{m} / \mathrm{rad})$.

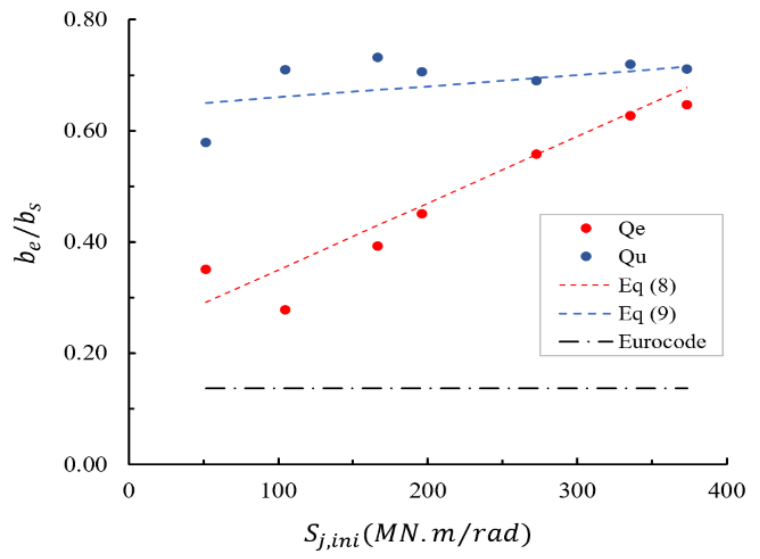

Fig. 20 Comparison of the proposed formulas Eq. (8) and Eq. (9) against the predicted FE results

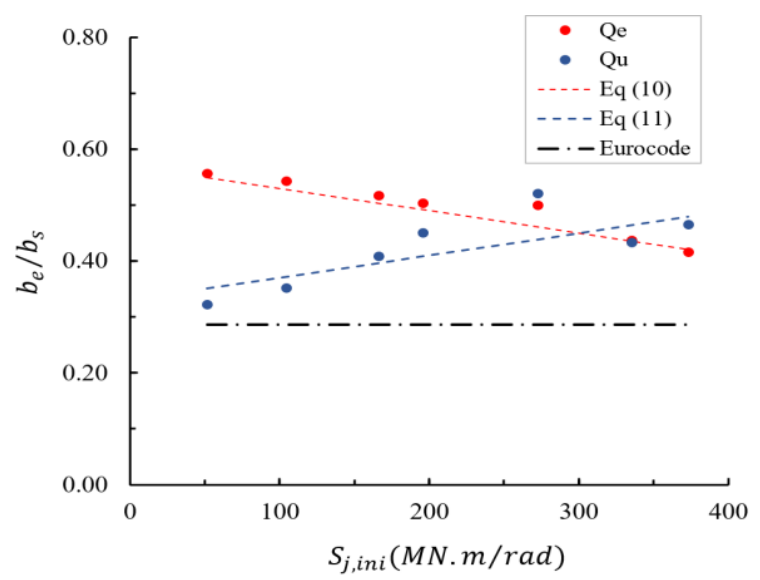

Fig. 21 Comparison of the proposed formulas Eq. (10) and Eq. (11) against the predicted FE results

The so-proposed formulas are promising, and the validation of the formulas to other composite beam configurations can be seen as a perspective to the present work.

\section{Conclusions}

A reliable FE model has been developed through the conducted investigations for continuous and semi-continuous composite beams. In particular, the validity of the continuous composite beam model was verified and validated by comparing the numerical results to experimental ones. A simplified model was developed to simulate the presence of semi-rigid joints in the composite beam, and the component method was used to determine the associated initial stiffness of the composite joint. With these numerical models, it was possible to accurately predict the load-deflection response of the investigated continuous and semi-continuous composite beams and evaluate the associated effective slab widths along the beams. An extensive parametric study was conducted to identify the influence of some key parameters on the effective widths. As a result, it was demonstrated that the slab width and the joint stiffness significantly influence the effective width, while the effect of the degree of connection is negligible.

Finally, simplified design formulas were proposed to evaluate the effective widths considering the effect of the so-identified key parameters. The effective widths calculated with the proposed formulas predict the effective widths accurately compared to the numerical results. The formulas provided in this paper are based on the experimental findings of a specific set of geometrical and mechanical characteristics presented in Section 4 and Table 1. Further experimental studies are required to explore the applicability of the proposed formulation to other composite beam configurations and better understand the behavior of composite continuous and semi-continuous beams, which constitutes a perspective to the presented work.

\section{Acknowledgment}

The authors gratefully acknowledge the support provided by the Urban and Environmental Engineering department at Liege University (Belgium) and the SREML research laboratory at Laghouat University (Algeria). Thanks, are also extended to the DGRSDT Directorate of the Ministry of High Education and Scientific Research of Algeria for providing a scholarship to enable this research work to be conducted.

\section{References}

[1] Yuan, H., Deng, H., Yang, Y., Weijian, Y. and Zhenggeng, Z., "Element-based effective width for deflection calculation of steel-concrete composite beams," Journal of Constructional Steel Research, 121, 163-172, 2016 Doi: https://doi.org/10.1016/j.jcsr.2016.02.010

[2] European Committee for Standardization (CEN), Design of composite steel and concrete structures, Part 1-1: General rules for buildings, EN 1994-1-1 Eurocode 4, Brussels, 2004.

[3] GB50017, Code for Design of Steel Structures, Beijing, Ministry of Construction of People's Republic of China, 2003.

[4] AISC, load, and resistance factor design specifications for structural steel buildings, Chicago, American Institute of Steel Construction, 2010.

[5] Amadio, C. and Fragiacomo, M., "Effective width evaluation for steel-concrete composite beams," Journal of Constructional Steel Research, 58(3), 373-388, 2002. Doi: https://doi.org/10.1016/S0143-974X(01)00058-X

[6] Amadio, C., Fedrigo, C., Fragiacomo, M. and Macorini, L., "Experimental evaluation of effective width in steel-concrete composite beams," Journal of Constructional Steel Research, 60(2), 199-220, 2004. Doi: https://doi.org/10.1016/j.jcsr.2003.08.007

[7] Salama, T., and Nassif, H. H., "Effective flange width for composite steel beams," The Journal of Engineering Research [TJER], 7(2), 28, 2011. Doi: https://doi.org/10.24200/tjer.vol8iss1pp28-43

[8] Lasheen, M., Shaat, A. and Khalil, A., "Numerical evaluation for the effective slab width of steel-concrete composite beams," Journal of Constructional Steel Research, 148, 124-137, 2018. Doi: https://doi.org/10.1016/j.jcsr.2018.05.015

[9] Al-Sherrawi, M. H. and Dawood, A. R., "Shear -lag in continuous composite steel-concrete beam," International Research Journal of Advanced Engineering and Science, vol. 4, issue 1, pp. 85-90, 2019

[10] Transportation Research Board and National Academies of Sciences, Engineering, an Medicine. Effective slab width for composite steel bridge members. Transportation Research Board, 2005 . Doi: https://doi.org/10.17226/13853

[11] Nie, J. and Tao, M., "Slab spatial composite effect in composite frame systems. I : Effective width for ultimate loading capacity", Journal of Engineering Structures, 38, 171-184, 2012 Doi: https://doi.org/10.1016/j.engstruct.2011.11.034

[12] Khalaf, M., El-Shihy, A., El-Kasaby, E.-S. and Youssef, A., "Numerical estimation and analysis of effective width of composite beams with ribbed slab," International Journal of Application or Innovation in Engineering and Management 3 (8) 1-15, 2014

[13] Dezi, L., Gara, F. and Leoni, G., "Effective slab width in prestressed twin-girder composite decks," Journal of Structural Engineering, 132(9), 1358-1370, 2006. Doi: https://doi.org/10.1061/(ASCE)0733-9445(2006)132:9(1358)

[14] Gara, F., Leoni, G., and Dezi, L., "A beam finite element including shear lag effect for the time-dependent analysis of steel-concrete composite decks," Journal of Engineering Structures, 31(8), 1888-1902, 2009. Doi:https://doi.org/10.1016/j.engstruct.2009.03.017

[15] Nicoletti, R. S., Rossi, A., Souza, A. S. C. de and Martins, C. H., "Numerical assessment of effective width in steel-concrete composite box girder bridges," Journal of Advances in Structural Engineering, 24(5), 977-994, 2021. Doi: https://doi.org/10.1177/1369433220971744

[16] Gara, F., Ranzi, G., \& Leoni, G., "Partial interaction analysis with shear-lag effects of composite bridges: a finite element implementation for design applications.", Journal of Advanced Steel Construction, 7(1), 1-16, 2011. Doi: https://doi.org/10.18057/IJASC.2011.7.1.1 
[17] MathWorks, Inc. MATLAB R2016a. Natick, MA: Math Works, Inc.; 2016.

[18] ABAQUS, ABAQUS Analysis User's Guide, Version 6.14, Dassault Systèmes Corp., Providence, RI (USA), 2014.

[19] Thai, H.-T. and Uy, B., "Finite element modeling of blind bolted composite joints," Journal of Constructional Steel Research, 112, 339-353, 2015.

Doi: https://doi.org/10.1016/j.jcsr.2015.05.011

[20] Aribert , J. and Al Bitar , A., "Optimisation du dimensionnement en connexion partielle de poutres de planchers mixtes réalisés avec un bec en tôle mince nervurée", La revue Construction métallique 26 (4) 3-33, 1989.

[21] Yun, X. and Gardner, L., "Stress-strain curves for hot-rolled steels," Journal of Constructional Steel Research, 133, 36-46, 2017.

Doi: https://doi.org/10.1016/j.jcsr.2017.01.024

[22] Carreira, D. J., and Chu, K. H. "Stress-strain relationship for plain concrete in compression," ACI Journal Proceedings, 82(6), 1985.

Doi: https://doi.org/10.14359/10390

[23] Al-Jabri, K. S., Pillay, P., Waris, M. B. and Pervez, T., "Modeling of composite beam-column flexible endplate joints at elevated temperature," Journal of Composite Structures, 143, 180188,2016

Doi: https://doi.org/10.1016/j.compstruct.2016.01.069

[24] Dai, X. H., Wang, Y. C., and Bailey, C. G., "Numerical modeling of structural fire behavior of restrained steel beam-column assemblies using typical joint types," Journal of Engineering Structures, 32(8), 2337-2351, 2010.

Doi: https://doi.org/10.1016/j.engstruct.2010.04.009

[25] Janss, J. and Jean-Claude, L., Essais de poutres mixtes sur troisappuis, Centre de Recherches Scientifiques et Techniques de l'Industrie des Fabrications Métalliques, Bruxelles, 1973

[26] Che, S. and Zhang, Z., "Effective width of a concrete slab in steel-concrete composite beams prestressed with external tendons," Journal of Constructional Steel Research 62 (5) 493-500, 2006.

Doi: https://doi.org/10.1016/j.jcsr.2005.08.009

[27] CEN. EN 1993-1-8. Eurocode 3: Design of steel structures, part 1-8: Design of joints, Brussels: CEN; 2005. 